\title{
EL SURGIMIENTO DE LO TRÁGICO Y NUEVAS FORMAS DE INSURRECCIÓN SOCIAL
}

\author{
Michel Maffesoli* \\ Lorenzo Agar Corbinos**
}

\begin{abstract}
Resumen: En el medio urbano se manifiesta una insurrección latente y manifiesta, con expresiones múltiples y cada vez más variadas e imaginativas. La violencia se muestra con su expresión física y también con una expresión de odiosidad contra lo instituido y contra el tipo de relaciones sociales e interpersonales vigentes. Es necesario reflexionar sobre lo impensable, sobre aquello que creíamos impenetrable desde lo no-racional. Pensar el no-racional está muy lejos de ser irracional. El gran fantasma de la asepsia social ha pretendido expulsar la sombra que roe el cuerpo individual y colectivo. El análisis, en términos de contrato social, de ciudadanía, de ideal democrático, ha sido incapaz de explicar los estallidos de pasión y emociones tribales. La pregunta es cómo enfrentar esta realidad social en ebullición, con las limitaciones normativas y morales.
\end{abstract}

Palabras clave: Insurrección, relaciones interpersonales, no-racional, contrato, democracia

\section{TRAGIC UPRISING AND NEW FORMS OF SOCIAL INSURRECTION}

\begin{abstract}
Urban areas are experiencing a latent rebellion, which is manifesting itself in numerous forms; each wave the culmination of increasing variety and imagination. Violence, a physical expression of this rebellion captures the hatred felt towards the establishment, in particular towards the prevailing social networks and societal relationships currently in force. It is therefore necessary to reflect upon the unthinkable, over that which we have considered unthinkable since the non-rational: to think that the non-rational is far from being irrational. The spirit of this great social asepsis has sought to expel the darkness, which corrodes both the body of the individual and society as a whole. Analysis, in terms of social contract, citizenship, and a democratic ideal has been incapable of explaining the aforementioned detonation of tribal passion and emotion. The question that we now face is how must we confront this flammable reality within the bounds of normative ethics and morality.
\end{abstract}

Keywords: Insurrection, interpersonal relationships, non rational, contract, democracy

\section{SURGIMENTO DA COISA TRÁGICA: AS NOVOS FORMAS DA EXPRESSÃO SOCIAL}

Resumo: No meio urbano manifesta-se uma insurreição latente com expressões múltiplas de formas cada vez mais variadas e imaginativas. A violência urbana apresenta-se como expressão física, ódio contra o instituído e contra o modelo de relações sociais e interpessoais vigentes. É necessário refletir sobre o impensável, sobre aquilo que julgávamos indecifrável desde o não-racional. Pensar o não-racional está muito distante de ser irracional. O grande fantasma da assepsia social pretendeu expulsar a sombra que corroe o corpo individual e coletivo. A análise, em termos de contrato social,cidadania e ideal democrático foi incapaz de explicar as explosões de paixão e emoções tribais. A pergunta que se apresenta é de como enfrentar esta realidade social em ebulição com as limitações normativas e morais.

Palavras chave: Insurreição, relações interpessoais, não-racional, contrato, democracia

\footnotetext{
* Profesor de La Sorbona, Universidad de París V. Director del Centro de Estudios sobre lo Actual y Cotidiano, París V Correspondencia: michel.maffesoli@univ-paris5.fr

** Profesor del Departamento de Sociología de la Facultad de Ciencias Sociales de la Universidad de Chile. Consultor Residente del Programa Regional de Bioética OPS/OMS.

Correspondencia : agarl@chi.ops-oms.org
} 
¿Se repite la historia? Lo cierto es que a lo largo de largos períodos, ella nos refresca la memoria, en particular recordándonos que el mal es inherente a nuestra pobre naturaleza humana. El humus dentro de lo humano.

Max Weber, incitando a meditar la enseñanza de Nietzsche y previamente la de Las flores del mal de Baudelaire, muestra claramente que, en el momento de instaurarse el orden racional moderno, una cosa puede ser "verdadera" aunque no sea ni bella ni buena. El sentido común sabe también, a su manera, que el infierno está plagado de buenas intenciones.

Tal lucidez, que parece faltar a varios observadores sociales, adquiere una convicción incluso más grande en una época donde se acaba la modernidad. Ellos ven caer "sorprendidos" sobre sus cabezas el trueno que no habían previsto. Terrorismo, guerras tribales de distintos índoles y, en nuestro entorno urbano, en nuestro vecindario, insurrección latente y manifiesta, con expresiones múltiples y cada vez más variadas e imaginativas. La violencia se muestra con su expresión física y también con una expresión de odiosidad contra lo instituido y contra el tipo de relaciones sociales e interpersonales vigentes.

Frente a este regreso de lo trágico, es posible continuar con los ojos cerrados, es posible también desentenderse de la ruidosa sublevación que se inicia en todas partes. O bien, asustado, taparse medrosamente la cara frente al regreso de lo bárbaro. Esto no impide que dicho regreso sea evidente. Nuestra tarea es, pues, aprender a reflexionar sobre lo impensable, sobre aquello que creíamos impenetrable desde lo no-racional.

Eso no se realizará profesando los encantamientos racionalistas que se han transformado en las doxa intelectuales. Contrariamente al conformismo de las opiniones comunes, pensar el no-racional está muy lejos de ser irracional. Todo lo contrario. Quizá esto corresponda a las flores del mal postmodernas (este "verdadero" que no es ni bueno, ni bello). ¿Existe un regreso con fuerza de lo que continuamente se ha negado?. Imaginario de todo orden, "ilusiones" religiosas, creencias diversas, sentimiento de pertenencia comunitario y otros fenómenos emocionales. Cosas que escapan a la lógica mecánica de un social dominado por la razón instrumental.

Se puede ciertamente preferir una sociedad o un conjunto de sociedades, nacionalmente o internacionalmente, dirigidas bajo el ideal democrático, el del contrato libremente consentido. Pero esa moral del "deber ser" ha amputado el cuerpo social, de una manera drástica y totalitaria, de otras dimensiones humanas como son lo onírico, lo lúdico, los imaginarios colectivos o el deseo de vibrar juntos. Y, al igual que el regreso a la conciencia de lo censurado, estas dimensiones se están cobrando su revancha.

Una revancha salvaje, sanguinaria. La exclusión de lo que era considerado como un "mal" conduce de hecho a su exacerbación. Un "mal" que no es tratado con dosis homeopáticas tiende a contaminar a todo el cuerpo social. Al mismo tiempo, el universalismo de los valores elaborado minuciosamente en un pequeño rincón del mundo, universalismo occidental que tuvo su eficacia durante la era moderna, se ve desacomodado cuando resurgen los mitos característicos de las tradiciones locales, enraizadas en los particularismos nuevamente presentes, muy a pesar de las "ideas" globalizadoras. Se observa con claridad que mientras más se intenta globalizar con una fuerza similar o aun mayor resurgen las particularidades culturales. Y también puede aplicarse esta misma secuencia de acción para los individuos y sus relaciones humanas.

El gran fantasma de la asepsia social, llevando a la fantasía del "riesgo cero", ha 
pretendido expulsar la sombra que roe el cuerpo individual y colectivo. Partiendo desde los higienistas del sigo XIX y otros filántropos "iluminados", hasta el "vigipirata", plan antiterrorista a la francesa, la lógica es idéntica: erradicar la aventura, lo imprevisible, lo animal dentro lo humano. Temer a todo y sobre todo a su propia sombra. El orden abstracto lleva siempre a un tipo de sociedad donde la seguridad y el bienestar se pagan con la certeza de morirse de aburrimiento.

Emanan de allí, las rebeliones juveniles, el desinterés hacia lo político, los terrorismos, las creencias arcaicas, los simbolismos diversos, los integrismos y fanatismos de todos tipos, que vuelven a tomar fuerza y vigor, sorprendiendo las buenas intenciones del moralismo ambiente. Empero, al mismo tiempo, esos fenómenos son la expresión, más o menos perversa, de una vitalidad reencontrada. Sin ir más lejos podríamos incluir en nuestro análisis los desnudos masivos que se han producido en varias ciudades del mundo occidental organizados por el fotógrafo Spencer Tunick y que han generado debates morales y éticos de gran interés.

Aunque esta comparación pueda aparecer como chocante, existe en las efervescencias musicales, en los actos sociales y deportivos masivos, en la violencia urbana, en las manifestaciones anti-globalización, así como en el terrorismo y la indiferencia política latente, el mismo deseo de romper con un orden vertical, patriarcal, civilizado, que cree saber con certeza lo que es el bien e intenta imponerlo en forma totalitaria a todo el planeta.

El análisis, en términos de contrato social, de ciudadanía, de ideal democrático, es incapaz de explicar los estallidos de pasión y emociones tribales. Estallidos que en todos los ámbitos - profesional, cultural, sexual, entre muchos otros - de la vida colectiva e individual, se encuntran sólo en su inicio.

La geopolítica es también incapaz de analizar el resurgimiento de las pasiones en las distintas sociedades.

Ya sea en la ex-Yugoslavia, en Nigeria, en Palestina, en Algeria o en Afganistán, en la memoria imperecedera de culturas y religiones, a las cuales fue negado todo reconocimiento, es posible encontrar alguna explicación a la nueva aparición trágica de masacres, exterminaciones y otros terrorismos suicidas.

Es este impensable el que nos debe hacer pensar. Y ya no, simplemente, a través de nuestras categorías heredadas de los grandes sistemas filosóficos elaborados en los siglos XVIII y XIX, ni tampoco a partir de un moralismo universalista algo obsoleto, sino más bien considerando estos fenómenos por sí mismos, tratando de descubrir la razón interna que los impulsa.

De hecho, ésta es la de una erótica colectiva: deseo y placer del riesgo, pulsión de la pérdida del sujeto individual en una subjetividad de masa. En un sentido estricto, el "gasto" que también puede hacer cultura. No se explicaría de otra manera estos actos de "suicidio" terrorista. Afirmaciones de valores inmateriales, en contra de las leyes implacables de un economicismo obtuso. La importancia creciente de una nueva forma de encuentro y relación social en una comunidad territorialmente arraigada.

Se podría decir que nos enfrentamos actualmente, en un sentido lato, a una mentalidad orgiástica.

Es esta erótica religiosa, de lenguaje, emocional, erótico bárbara, sangrienta o sim- 
plemente cotidiana, que escapa a los racionalismos económicos y geopolíticos de los diversos análisis actuales. Es ella la que, contra los diversos poderes, recuerda la fuerza de la potencia básica, la que hace de una pérdida una ganancia. El éxtasis está a la orden del día. No basta con estigmatizarlo, más bien es necesario detectar la lógica pasional.

No cabe entonces hablar de los "eventos del 11 de septiembre" y de sus consecuencias. Al igual que los eventos del 68, llamarlos así reduce su alcance. Se vuelven a codificar dentro del esquema político o histórico, buscando adherir a una racionalidad, o una irracionalidad, acabada.

No consiste en un mero "choque psicológico", con sus consecuencias económicas, sino más bien de un fuerte remezón en el inconsciente colectivo.

Por lo tanto, convendría mejor hablar de un advenimiento. El del resurgimiento de las comunidades de destino, compartiendo valores "arcaicos" es decir primarios, fundamentales. El de las emociones y de las pasiones localizadas que, contrariamente y en contra de la uniformidad del mundo, atestiguan el retorno a la compleja entereza de la naturaleza humana.

Nos encontramos claramente en presencia de una verdadera cultura de sentimientos. La cultura no es solamente un punto de vista racional, más bien pone en juego afectos. Cultura que se encarna y que, por lo tanto, integra a todos los elementos de tal encarnación, incluyendo el aspecto perecible de la carne.

La intensidad erótica se desprende del vínculo entre "Eros" y "Tanatos", cuyo aspecto del gozo, en el grado más alto del deseo, recuerda todo lo que lo une a la muerte.
En la explosión terrorista o en la rebelión cotidiana, al igual que en la secesión civil, es sin duda alguna una ambivalencia de esta envergadura lo que se expresa. Lo emocional, el compartir afectos y dolor, tal como un órgano para la felicidad y su opuesto. Los protagonistas de la Revolución Francesa consideraban la felicidad como una "idea nueva" que había que promover. Sabemos lo que ocurrió. Parece que hemos dejado atrás esta pretensión y que se ha dado inicio, permeando todos los ámbitos de la vida, a una apreciación más justa de las cosas. Vivir, al día, el dolor y el mal otorgándoles un valor más común, menos excepcional.

La interrogante consiste en cómo poder enfrentar esta realidad social en ebullición. La sociedad, palabra "usada" y "utilizada" como referente de análisis sociológico, está rodeado de espinas normativas y morales. La socialidad se relaciona con la ética.

Así, cuando predominan los lugares comunes, las buenas intenciones y demás ideas aceptadas, es necesario retornar a ciertas banalidades básicas como, por ejemplo, la que estipula que la vida precede las reglas que se da para poder perdurar. Durkheim ya había anotado que "la ley sólo sigue las costumbres".

Si bien es cierto se trata de banalidades, es conveniente recordar, con la ayuda del moralismo reinante, que es bien visto por los dueños de la sociedad, usar y abusar de las leyes por conveniencias personales. En forma individual o colectiva, el espíritu de procedimiento legalista es siempre el síntoma de una falta de seguridad interna. Una civilización segura de sí misma encuentra su equilibrio en forma natural. Las leyes que dicta tienen como único propósito canalizar los excesos de vida que podrían ocurrir y tornarse en su contra.

Esto es totalmente distinto en épocas menos dinámicas, donde las reglas no son sim- 
ples contendores sino, por el contrario, los amuletos de un cuerpo con síntomas de atonía y envejeciendo. En esas épocas, la ley antecede y reprime la vida. Es instrumentalizada de esta manera, pierde su carácter concreto ("cum creceré" significa "que crece con") para ser abstracta y en muchos aspectos, mortífera.

Pensamos en lo que decía el viejo Marx: "la burguesía no tiene moral, utiliza la moral". Podemos extrapolar lo anterior y aplicarlo a la ley. Son varios, tanto individuos como instituciones, los que se sirven del derecho cuando les conviene y lo burlan de manera ultrajante cuando no. Consiste en una actitud de alto riesgo, no tanto por los individuos o las instituciones involucradas (tiene poca relevancia) sino por el cuerpo social en su conjunto.

En efecto, someter a otros a unos "imperativos categóricos" a los cuales no se astringen, es la forma más segura de provocar efectos perversos, tales como los múltiples actos violentos que acompañan a diario nuestra vida urbana. Cada individuo se enfrenta en un momento u otro a una de esas formas de expresión de aquella secesión.

Es fácil incriminar a los protagonistas o analizarlos a través de las habituales categorías socioeconómicas en vigor. $\mathrm{O}$ bien se les estigmatiza de salvajes delincuentes, ignorantes de los valores comunes republicanos, o bien se condena la exclusión de la cual son objeto y que les impide comulgar con dichos valores. En ambos casos se aplican de una manera mecánica, viejas recetas modernas según las cuales individuos racionales se asociarían en forma voluntaria en un contrato social también racional. Este es el débil análisis que efectúa el conformismo intelectual.

No obstante, una investigación más profunda y divergente en su estructura y método permite detectar en las insurgencias coti- dianas, los índices más fieles de aquellos fenómenos ya mencionados y que surgen regularmente a lo largo de la historia. Por una parte la inadecuación de la ley a los usos y costumbres, por otra parte el abuso de esta ley por parte de los que son sus garantes. Es necesario que estemos atentos y enfrentemos con gran lucidez la saturación del mecanismo de representación. Cada época elabora los mitos y demás imaginarios que hacen de ella lo que es. Nuestra(s) representación(es) se ha(n) forjado progresivamente a lo largo de los últimos tres siglos. Puede resumirse a través de la bella expresión de Hannah Arendt como del "ideal democrático". Es ese ideal, que fue la causa y el efecto de la "representación política" el que ha moldeado las generaciones (de todas la tendencias) y ha detentado el poder de hablar o de actuar.

Repitamos otra banalidad tan obvia que no se ve: es difícil para una parte cada vez más importante de la población, reconocerse en esas representaciones filosóficas y políticas. Existe un abismo, un desfase, mientras el cinismo se expande impunemente.

Es ciertamente destacable, en aquellas épocas en las cuales un mito importante de bien público se desvanece, que los que son aún los representantes se encuentren por encima de cualquier sospecha, que no sean objeto de burla ni desacreditados, de tal manera que gracias a su experiencia puedan ayudar al nacimiento de otro mito colectivo. Ellos deben ayudar y no proponer un modo de pensar o de vivir elaborado previamente o, peor aún, imponerlo.

Parece relevante hacer una diferencia esencial entre moral y ética. Es común confundirlos y hasta es usual reforzar uno con el otro juntando moral y ética. Es más "chic" contar con una moral, una ética, en vez de una visión moral y nada más. Se suele realizar constantemente esa confusión. 
Recordemos, sencillamente, que si la moral es general, universal, aplicable en cualquier lugar y momento, la ética en cambio es más particular y tiene sus raíces en la experiencia diaria. La moral viene de arriba, la ética parte de abajo.

Si bien existe una verdadera desconfianza frente a todo lo que está arriba, toda obligación legal y algo abstracta, existe una verdadera apetencia hacia todo lo que parece ser vivido en forma auténtica. La abstención política es la respuesta al legalismo o al moralismo instrumentalizado. Las nuevas formas de solidaridad, las innegables generosidades juveniles, el desarrollo del voluntariado "tribal" son actitudes en búsqueda de una ética de proximidad. Sucede lo mismo con las agitaciones de todo tipo, ya sean deportivas, musicales o religiosas. Pueden estar en varios aspectos, fuera de la ley o inmorales, constituyen sin embargo un nuevo vínculo social en gestación. Corroboran el certero adagio según el cual lo anómico de hoy es lo canónico de mañana.

Vamos a ser confrontados cada vez más a una verdadera desconfianza frente a la ley abstracta y/o a aquéllos que usan y abusan de ella por su propio interés, ya sea en forma individual o grupal. La abstención, las violencias, las insurrecciones, las indiferencias sociales y políticas son las resultantes más destacadas. Otras épocas conocieron tales "secessio plebis".
No obstante, existe al mismo tiempo el deseo de una figura emblemática alrededor de la cual es posible agruparse. Figura que haga vibrar y que reconforte el sentimiento de pertenencia. Deseo de una "autoridad" que en el sentido etimológico, sepa "hacer crecer" los innegables valores de una cultura en gestación.

Una autoridad así, enraizada, puede permitir al cuerpo social tomar conciencia del inconsciente colectivo que es suyo, es decir encontrar las palabras que necesita para (re)fundar, siempre y de nuevo, el estar-juntos.

Aquí reside el carisma: saber decir lo que un pueblo desea decir sobre el mismo. "Inventar", o sea crear, el imaginario que necesita para existir, para "adecuarse" a los otros y al mundo, y de esa manera vivir su propia soberanía. Lo que emerge desde las raíces de la vida en comunidad es la búsqueda de aquellos puntos de encuentro que digan relación con un compartir ético de la socialidad por sobre lo tradicional, lo que nos aferra a un pasado en vías de extinción, que corresponde a vivir en función de una moral social. La reflexión en las ciencias sociales debe tomar en consideración esta nueva realidad y aceptar que nuevas formas de relación humana están surgiendo y que será necesario utilizar nuevos esquemas de interpretación y modelos para la acción, considerando el sentimiento y la intuición en un lugar tanto o más destacado que el tradicional pensamiento empírico. 